\title{
Validation of Instruments to Assess Home Food Environment of Pre-Adolescents: A Pilot Study
}

\author{
Martha J. Nepper, McKena Ludemann and Weiwen Chai* \\ Department of Nutrition and Health Sciences, University of Nebraska-Lincoln, Lincoln, NE
}

Received: September 27, 2014; Accepted: December 15, 2014; Published: December 30, 2014

*Corresponding author: Weiwen Chai, Department of Nutrition and Health Sciences, University of Nebraska-Lincoln, Lincoln, NE, USA, Tel: +402-472-7822; Fax: 402-472-1587; E-mail: wchai2@unl.edu

\begin{abstract}
Background: Assessing the home food environment is important for elucidating the underlying causes of childhood obesity; however, few instruments have assessed the visibility of foods in the home along with their availability and accessibility. The purpose of this pilot study was to validate a Home Food Assessment tool (HFA) to evaluate the availability, visibility and accessibility of actual home foods and a 30-day Home Food Environment Survey (HFES) to assess the foods regularly present in the homes of pre-adolescents.
\end{abstract}

Methods: Thirteen pairs of parents and their children aged 9 to 12 years participated in the study in 2014. The HFA was completed by the research staff and parents independently for criterion validity. Kappa statistics was used to compare parent and staff reports. Parents also completed HFES during the home visit and one week after for test-retest reliability which was analyzed using the IntraClass Correlation Coefficient (ICC). Cronbach's alpha was used to test the internal consistency of the instruments.

Results: Of the 23 healthy and unhealthy items from HFA, moderate to outstanding agreement $(0.41-1.00)$ between research staff and parents was observed on 21, 14, and 18 items for availability, visibility and accessibility, respectively. Two items had low agreement scores for all three categories (availability, accessibility and visibility) and therefore were either modified or removed. Agreement levels for items of fresh fruits and vegetables ranged from moderate to outstanding (0.41-1.00), with the exception of four items. Internal consistency for 12 healthy food, 11 unhealthy food, 18 fresh fruit, and 14 fresh vegetable items were 0.94, 0.91, 0.90 , and 0.87 , respectively. For HFES, ICCs for test-retest reliabilities were high (0.69-0.96) except for two reduced-fat items. The total scores of the available healthy ( $r=0.87, P=0.0001)$ or unhealthy items $(r=0.85, P=0.0005)$ from the HFA were positively correlated to those from HFES.

Conclusion: Our results demonstrated that HFA and HFES are participant-friendly, reliable and valid instruments to assess the home food environment of pre-adolescents. These two instruments complement each other and are useful for future research in exploring the relationship between home food environment and weight status of pre-adolescents.

Keywords: Home food environment; Availability; Accessibility; Visibility; Pre-adolescents

\section{Background}

Childhood and adolescent obesity is a major public health concern in the United States. Currently, 32.4\% of children and adolescents, aged 6-19 years, in all ethnicity groups are overweight, and $16.5 \%$ are obese [1]. Obese children and adolescents are more likely to become obese adults, which may cause increasing rates of health complications in the future adult population[2]. The ecological model provides frameworks for understanding how a variety of environmental factors influence eating behaviors $[3,4]$. The home environment is one of the most important settings in regard to a child's dietary intake [5] since $65 \%$ to $72 \%$ of daily calories are consumed in the home [6]. Research suggest that if healthy foods are available and accessible in the home, children are more likely to eat these types of foods [7]. Also, parents are seen as the nutritional gatekeepers and directly influence the types of foods stored and consumed in the home [8].

Several studies indicate that children and adolescent's eating habits are directly related to the availability and accessibility of foods in the home [9-11]. Food availability refers to the actual presence of the food in the home (e.g., in cupboards, refrigerators, freezers or other food storage spaces) [12], and accessibility represents foods that are retrievable, ready to eat, and in a location that facilitates their consumption [13]. Research suggested that homes with healthy weight children are more likely to have healthier food options available and limit access to unhealthy foods [14]

Previously assessing the home food environment has typically involved self-report inventories that examined food availability in the home and have captured the presence of foods at a certain point in time $[9,11,15,16]$. Ideally, instruments measuring the foods in a home should take into account what is actual available at the time of the inventory, as well as foods that are usually available over a certain time period (e.g., 30 days), which will reflect the variation in shopping episodes [15].

Recently, researchers have begun to include observational methods to provide more objective measurements of the home food environment and to reduce the potential bias of self-report. For example, Bryant et al. [17] conducted a telephone survey and 
a subsequent in-home assessment for the presence of healthy and unhealthy foods among 85 families with a child between the ages of 3 and 8 years. Boles et al. [18] developed an in-home observational assessment tool to compare the differences in more than 20 home food and drink items based on their availability, accessibility and readiness to eat between healthy weight and obese preschoolers. The results from 82 families suggested that homes of obese children were less likely to have fresh vegetables available, whereas, parents of healthy weight preschoolers provided children more access to healthier foods and made fruits and vegetables more readily to eat. The Home Food Inventory survey developed by Fulkerson et al. [19] assessed home food availability of 13 major food categories and ready access to foods in the kitchen and the refrigerator. In their study, the Home Food Inventory survey was completed by both the research staff and the study participants. The results demonstrated high kappa scores and correlations between participants' and staff's reports on foods in the home [19]. Given the consideration that entering private households and conducting an inventory of foods in the homes may create potential participant and researcher burden and inconvenience, having a home food assessment tool that can be independently completed by the participants appears necessary.

While the existing food inventories have categorized wide ranges of foods in the home related to availability, accessibility, and readiness to eat [17-19], few tools, however, have been developed to examine the visibility of foods. Food visibility refers to food that is on the countertops, top of refrigerators, or a person is able to see the food when opening the refrigerator and freezer without moving any items, which may increase the attention to food and influences the amount and type of food eaten at home [20]. Research suggest that foods that are preferred by a child in a visible place in the home are more likely to lead to a greater consumption of that food [21]. In a study with 90 overweight adults who participated in a six-month weight loss program, the researchers found that participants who removed visible foods from their countertops, living room tables, and kitchen tables were more likely to consume fewer calories and lose weight compared to those who didn't [22]. Wansink et al. [20] reported that although participants ate more, they tended to underestimate the amount they had consumed when foods like candies were visible and proximate. On the other hand, a basic availability bias may cause people to overestimate the incidence or quantity of food items that they consider more available or relevant in their memories [23]. Therefore, taking visibility of foods into account will allow researchers to be more accurate in assessing the home food environment as well as help parents be more effective in monitoring and controlling their children's food intake. In addition, few home food assessment tools have been created for pre-adolescents, an important stage of life where lifestyle habits such as healthy eating, are formed. The purposes of the current study were: 1) to validate a participant-friendly, Home Food Assessment tool (HFA) that assesses the availability, accessibility and visibility of both healthy and unhealthy food and beverage items in the home of children, aged 9 to 12 years (preadolescents); 2) to compare the results of HFA completed by the research staff to those completed by the parents in the home; and 3) to test the reliability of a brief 30-day Home Food Environment Survey (HFES), which assesses the usual availability of foods in the home over a 30-day period.

\section{Methods}

\section{Survey Development}

The Home Food Assessment tool (HFA) was developed to assess the availability, accessibility and visibility of healthy and unhealthy foods and beverages in the home and adapted from the instrument developed by Boles et al. [18]. The "readiness to eat" category was changed to "visibility" to determine the types of food items that may be sitting out on the countertops, kitchen or dining room tables, the top of refrigerator, and on living room end tables or in the refrigerator or freezer that are visible without moving any other food items.

Based on other previously validated instruments [18,19], the current measurement tool reflected 23 food items classified as "healthy foods and beverages" and "unhealthy foods and beverages" and fresh fruits (18 items) and fresh vegetables (14 items). A "yes/no" format was used to indicate availability, accessibility and visibility of these foods. Healthy food choices were defined as: fresh fruits and vegetables; reduced-fat cakes, cookies and pastries (already made); baked chips and pretzels; whole grain and low sugar cereal, breads, tortillas, brown rice and pasta; reduced-fat cheese, yogurt and ice cream; bottled water; $100 \%$ fruit juice; sugar-free sodas; and $1 \%$ or skim milk. Items belonging to unhealthy food category were: regular cakes, cookies and other pastries (already made), regular chips, juice drinks, regular sodas, sports drinks, $2 \%$ or whole milk; and sweetened breakfast cereals $[18,24]$. Classifications of these foods and drinks generally followed the Nutritional Standards for School Meals from the USDA National School Lunch Programs [24]. To increase the reliability of coding items, operational definitions of availability, accessibility and visibility of food and drink items were developed, in addition to specific nutritional content to help identify certain food items (e.g., sweetened breakfast cereal: $>6$ g sugar/serving). These definitions were described as follow: availability, a food exists in the kitchen, bedrooms, basement, garage or other rooms regardless of whether it is readily visible or accessible to the child; accessibility, a food that is retrievable, ready to eat, or in a location where is easy for a child to reach it; and visibility, a food that is on the countertops, top of refrigerators, or a child is able to see the food when opening the refrigerator and freezer without moving any items.

The corresponding 30-day Home Food Environment Survey (HFES) was adapted from the instrument by Gattshall et al. [16]. The majority of food items in HFES reflected those on the Home Food Assessment tool (HFA) and was used to assess the usual availability of foods in the home over a 30-day period. A five-point scale (never, rarely, sometimes, frequently or always) was used for survey responses and was scored on a scale of 0-4 with " 0 " referring "Never" and "4" referring "Always". "Never", "Rarely", "Sometimes", "Frequently", and "Always" were defined as $0 \%, 25 \%, 50 \%, 75 \%$, and $100 \%$ of the time, respectively. 


\section{Participants and Study Procedures}

The current investigation was conducted in 2014. The University of Nebraska-Lincoln Institutional Review Board approved this study. Parental consent and youth assent were obtained from all the participants before data collection. The children and their parents were recruited from the local communities using convenience sampling. Eligibility criteria includes having a child between 9-12 years of age, weight above the $5^{\text {th }}$ percentile for age and sex to avoid underweight children [25], and parents fluent in English. Pre-adolescents' weight and height were measured with standard anthropometric procedures during the home observation. Children are weighed with light clothing and no shoes using a weight scale and portable stadiometer, with measurements taken three times to ensure accuracy. Child's Body Mass Index (BMI) for age percentile was calculated using Center for Disease Control and Prevention growth charts [25]. Weight categories are defined as follow: $\geq 95^{\text {th }}$ percentile, obese; between the $85^{\text {th }}$ and $95^{\text {th }}$ percentile, overweight; and between the $5^{\text {th }}$ and $85^{\text {th }}$ percentile, healthy weight [26].

Prior to the home visit, participants were instructed not to change their food buying habits or contents of their refrigerator, freezer, cupboards or countertops in any way before the home visit. Demographic information was collected that included age, race, and gender of parent and child, family income, education and working status of parents. Two trained research staff visited the homes and together viewed the insides of refrigerators, freezers, kitchen cupboards and countertops. Also, the research staff asked parents if other food storage areas were in the home and what foods were in these areas, and the parents provided that information verbally. Therefore, researcher staff only visited the kitchen area to reduce the intrusiveness when completing HFA. If an item on HFA was coded "no" on availability, no further rating (availability and accessibility) on this item was completed. If an item was available in the home, then accessibility and visibility were rated. The HFA was also completed by parents during the home visit to test for criterion validity. Although participants and staff complete the assessment tool simultaneously, they were instructed not to communicate with each other during the process. The parents also completed the 18-item 30-day Home Food Environment Survey (HFES) at the home visit and one week later for test-retest reliability.

\section{Statistical analysis}

SAS software version 9.3 (SAS Institute, Inc., Cary, NC) was used to perform all statistical analyses with a $p$ value of $<0.05$ considered statistically significant. To establish criterion validity for HFA, the research staff and parents each completed the survey independently. The research staff were considered the "gold standard" since they were trained on how to use the assessment tool [27]. Kappa statistics were calculated for each dichotomous item recorded by the research staff and the parent. Test-retest reliability for the items in HFES was examined using the Intra-class Correlation Coefficient (ICC). Guidelines for kappa classification and ICC were: 0.81-1.00, outstanding; 0.61-0.80, substantial; $0.41-0.60$, moderate; $0.21-0.40$, fair, and $<0.21$, poor agreement [28]. Pearson Correlation Coefficient (r) was used to examine whether there were correlations between the summary scores of total available healthy or unhealthy foods from HFES and from HFA. Correlations between test and retest summary scores of all the items in HFES were also computed using Person Correlation Coefficient. The internal consistency of the instruments and subscales was assessed using Cronbach's alpha with a value of 0.60 or higher considered acceptable [29].

\section{Results}

A total of 13 parent-child dyads participated in the study. The mean age of the parents was $40.2 \pm 4.9$ years, and the majority were the child's mother (92.3\%). $84.6 \%$ of the families had income $\geq \$ 50,000$ and $69.3 \%$ had college degrees or higher. The average age of children was $11.2 \pm 1.6$ years. $69.2 \%$ were White, $15.4 \%$ were African-Americans and $7.7 \%$ were Hispanic-Latinos. The overweight and obese children were $23.1 \%$ and $7.7 \%$, respectively (Table 1).

Kappa statistics (agreement between research staff and parents) for availability, visibility and accessibility for each healthy and unhealthy food item from HFA and internal consistency results were demonstrated in Table 2 . Of the 23 items rated for availability in the home, 19 showed substantial to outstanding agreements (0.53-1.00) and two had moderate agreement (0.43-0.47). The ratings for visibility had lower agreement scores compared to availability although the majority (14 of 23) had moderate to outstanding agreements (0.411.00 ) in this category (visibility). For accessibility, moderate to outstanding agreements (0.41-1.00) were observed on 18 items. Two items ("canned fruit in heavy syrup" and "wholegrain cereals, breads, tortillas, brown rice and pasta") received poor agreements for all three categories, availability, visibility and accessibility. Cronbach's alpha (internal consistency) for 12 healthy, 11 unhealthy, and all items (healthy + unhealthy items) were $0.94,0.91$, and 0.90 , respectively. In addition, when the scores of availability, visibility and accessibility were summarized for all the healthy or unhealthy food items in the survey, there were significant correlations between research staff and parent ratings (total healthy items: $r=0.84, P<0.0001$; total unhealthy items: $r=0.88, P<0.0001$ ).

The individual fresh fruit and vegetable items for availability, visibility and accessibility in HFA ranged from moderate to outstanding agreements (0.41-1.00), with the exception of the accessibility (0.38) and visibility (0.16) of strawberries, accessibility of tomatoes $(0.24)$ and lettuce $(-0.02)$ and visibility of carrots (0.26). Cronbach's alpha for the total of 18 fruit items and 14 vegetable items were 0.82 and 0.80 , respectively (Table 3).

Table 4, shows test-retest results for the 30-day Home Food Environment Survey (HFES). The ICCs for test-retest reliabilities of individual items were substantial to outstanding (0.69-0.96) except for two reduced-fat items ("reduced fat chips, baked chips or pretzels" and "reduced-fat cheese"). A significant correlation was also found between test and retest summary scores of all the items in the survey ( $r=0.90, P<0.0001)$. The Cronbach's alpha 
Table 1: Characteristics of Study Participants.

\begin{tabular}{|c|c|}
\hline \multicolumn{2}{|l|}{ Characteristics } \\
\hline \multicolumn{2}{|l|}{ Child (N = 13) } \\
\hline Age (year) & $11.2 \pm 1.6$ \\
\hline \multicolumn{2}{|l|}{ Gender, n (\%) } \\
\hline Male & $8(61.5)$ \\
\hline Female & $5(38.5)$ \\
\hline \multicolumn{2}{|l|}{ Race/ethnicity, n (\%) } \\
\hline Non-Hispanic White & $9(69.2)$ \\
\hline Hispanic or Latino & $1(7.7)$ \\
\hline African-American & $2(15.4)$ \\
\hline Asian-American & $0(0)$ \\
\hline American Indian or Native American & $0(0)$ \\
\hline Other & $1(7.7)$ \\
\hline Body mass index (BMI, Kg/m2) & $19.6 \pm 6.3$ \\
\hline \multicolumn{2}{|l|}{ Weight status, $\mathbf{n}(\%)^{*}$} \\
\hline Healthy weight & $9(69.2)$ \\
\hline Overweight & $3(23.1)$ \\
\hline Obese & $1(7.7)$ \\
\hline \multicolumn{2}{|l|}{ Parents $(\mathrm{N}=13)$} \\
\hline Age (year) & $40.2 \pm 4.9$ \\
\hline \multicolumn{2}{|l|}{ Gender, n (\%) } \\
\hline Male & $1(7.7)$ \\
\hline Female & $12(92.3)$ \\
\hline \multicolumn{2}{|l|}{ Parent educational status, $\mathbf{n}(\%)$} \\
\hline Some high school & $2(15.4)$ \\
\hline High school graduate & $0(0)$ \\
\hline Some college & $2(15.4)$ \\
\hline $\begin{array}{l}\text { College graduate (Bachelor's degree or } \\
\text { higher) }\end{array}$ & $9(69.3)$ \\
\hline \multicolumn{2}{|l|}{ Parent current work situation } \\
\hline Working full-time & 7 (53.9) \\
\hline Working part-time & $4(30.8)$ \\
\hline Stay-at-home caregiver & $1(7.7)$ \\
\hline Currently unemployed & $1(7.7)$ \\
\hline \multicolumn{2}{|l|}{ Single parent house-hold, $\mathbf{n}(\%)$} \\
\hline Yes & $2(15.4)$ \\
\hline No & $11(84.6)$ \\
\hline \multicolumn{2}{|l|}{ Family income, $\mathbf{n}(\%)$} \\
\hline$<\$ 15,000$ & $0(0)$ \\
\hline$\$ 15,000-\$ 49,999$ & $2(15.4)$ \\
\hline$>\$ 50,000$ & $11(84.6)$ \\
\hline
\end{tabular}

"Weight status for children was defined using body mass index-for-age percentiles (underweight, $<5^{\text {th }}$ percentile; healthy weight, $5^{\text {th }}-84^{\text {th }}$; overweight, $85^{\text {th }}-94^{\text {th }}$; Obese, $\left.\geq 95^{\text {th }}\right)$.

for the instrument with all the food items was 0.83. There was a significantly positive correlation between the total availability scores of all the healthy foods at home during the past 30 days before the home visit (from HFES) and the total scores of all the available healthy items on the day when the in-home assessment was conducted (from HFA) ( $r=0.87, P=0.0001$ ). Similarly, summary scores of all the available unhealthy food items from HFES were significantly, positively correlated to those from HFA $(r=0.85, P=0.0005)$.

\section{Discussion}

Developing a participant-friendly and reliable assessment tool to evaluate the home food environment of pre-adolescents is important to explore the relations between pre-adolescents' home food environment and their weight status, identify the potential deficits in this area, and develop tailored intervention programs for weight management. This Home Food Assessment tool (HFA) demonstrated acceptable validity and reliability 
Table 2: Internal Consistency (Cronbach's alpha) and Agreement Statistics on Food and Beverage Items from the Home Food Assessment Tool (HFA, $\mathrm{N}=13)$.

\begin{tabular}{|c|c|c|c|c|}
\hline Food and beverage item & $\begin{array}{l}\text { Kappa } / \% \\
\text { Agreement }^{*}\end{array}$ & $\begin{array}{l}\text { Kappa } / \% \\
\text { Agreement }^{*}\end{array}$ & $\begin{array}{l}\text { Kappa } / \% \\
\text { Agreement }\end{array}$ & $\begin{array}{l}\text { Cronbach's } \\
\text { Alpha }\end{array}$ \\
\hline & Available & Visible & Accessible & \\
\hline Unhealthy food and beverage items & & & & 0.91 \\
\hline Regular cake, cookies, brownies, muffins, donuts, pastries (already make) & 0.65 & 0.70 & 0.65 & \\
\hline Regular chips (e.g., potato chips, corn chips) & 0.58 & 0.05 & 0.58 & \\
\hline Sweetened breakfast cereal (not whole grain, $>6 \mathrm{~g}$ sugar/serving) & 0.58 & 0.65 & 0.58 & \\
\hline Canned fruit in heavy syrup & 0.14 & -0.11 & -0.15 & \\
\hline Fruit drinks (not $100 \%$ fruit juice) & 0.54 & 0.42 & 0.70 & \\
\hline Sports drinks (e.g., Gatorade) & 1.00 & 0.83 & 1.00 & \\
\hline Milk (whole, 2\% - any flavor) & 0.68 & 0.49 & 0.68 & \\
\hline Regular sodas or sweetened beverages & 0.84 & 0.83 & 0.70 & \\
\hline Regular cheese (e.g., American, cheddar, Swiss) & $1.00 \dagger$ & 0.68 & $1.00 \dagger$ & \\
\hline Regular yogurt (made with whole milk with or without fruit) & $1.00 \dagger$ & $1.00 \dagger$ & $1.00 \dagger$ & \\
\hline Regular ice cream or frozen dessert & 0.65 & 0.22 & 0.37 & \\
\hline Healthy food and beverage items & & & & 0.94 \\
\hline Reduced-fat cake, cookies, brownies (already made) & 0.43 & 0.43 & 0.43 & \\
\hline Pretzels or baked chips & 0.81 & 0.27 & 0.81 & \\
\hline $\begin{array}{l}\text { Whole-grain cereals, breads, tortillas, brown rice and pasta (labeled "whole grain" or } \\
\text { "whole wheat", }>3 \mathrm{~g} \text { fiber and }<6 \mathrm{~g} \text { sugar/serving) }\end{array}$ & 0.08 & 0.18 & -0.02 & \\
\hline Fresh ready-to-eat fruits (e.g., fresh apples, grapes, pre-cut melon, berries) & 0.75 & 0.81 & 0.75 & \\
\hline Fresh ready-to-eat vegetables (e.g., carrots, celery, pre-cut vegetables) & 0.67 & -0.03 & -0.29 & \\
\hline $100 \%$ fruit juice & 0.69 & 0.53 & 0.69 & \\
\hline Milk (skim, $1 \%$ - any flavor) & 0.83 & 0.24 & 0.83 & \\
\hline Bottled water & 1.00 & 0.26 & 1.00 & \\
\hline Reduced-fat cheese (e.g., low-fat cheddar, Swiss) & 0.47 & 0.75 & 0.33 & \\
\hline Reduced-fat yogurt (with or without fruit) & 0.75 & 0.35 & 0.75 & \\
\hline Diet sodas, unsweetened ice tea or diet lemonade & 0.53 & 0.41 & 0.67 & \\
\hline Reduced-fat or light ice cream, frozen fruit juice bar or frozen yogurt & 0.64 & 0.63 & 0.42 & \\
\hline All items (healthy + unhealthy food and beverage items) & & & & 0.90 \\
\hline
\end{tabular}

${ }^{*}$ Kappa statistics for comparing the assessments between research staff and parents on each item; Percent agreement was reported when research staff or parents showed no variability in assessment (coding), and thus it was not suitable for Kappa statistics.

†Percent agreement was used and calculated as follow: (number of agreements / number of agreements and number of disagreements) x $100 \%$

when tested among parents of pre-adolescents. It is known that the availability of foods in the home may be one of the best predictors of children's dietary intake and potential obesity risk [15]. Furthermore, additionally examining the influence of healthy or unhealthy foods visible in the kitchen is a necessary component of a home food assessment, as they may potentially increase a child's attention, resulting in greater consumptions of these visible foods.

Criterion validity was demonstrated by acceptable kappa scores for rating between participants and research staff on majority of the items from HFA. The relatively lower visibility agreement scores of three unhealthy and five healthy food items may be due to the participant not fully understanding the meaning of the term visibility. Although operational definitions of availability, accessibility and visibility were provided, the directions may not be clear to the participants since they were not trained regarding how to use the tool. Thus, instructions on the term visibility that is clear and easy to follow need to be given to the participants in the future studies. Additionally, unhealthy item like "regular ice cream or frozen dessert" and healthy items such as "fresh ready to eat vegetables" and "reduced fat cheese" had relatively lower accessibility agreement scores; however, these items had substantial agreements on availability, and therefore were remained in the final survey. There were two items, "canned fruit in heavy syrup" and "whole-grain cereals, breads, tortillas, brown rice and pasta" which had lower kappa scores in all three 
Table 3: Internal Consistency (Cronbach's alpha) and Agreement Statistics on Items of Fresh Fruits and Vegetables from Home Food Assessment Tool (HFA, N=13).

\begin{tabular}{|c|c|c|c|c|}
\hline Items & $\begin{array}{c}\text { Kappa/\% } \\
\text { Agreement }\end{array}$ & $\begin{array}{c}\text { Kappa/\% } \\
\text { Agreement }\end{array}$ & $\begin{array}{c}\text { Kappa/\% } \\
\text { Agreement }\end{array}$ & Cronbach's Alpha \\
\hline & Available & Visible & Accessible & \\
\hline Fresh fruits & & & & 0.90 \\
\hline Bananas & 0.85 & 0.85 & 0.85 & \\
\hline oranges & 0.41 & 1.00 & 0.41 & \\
\hline Apples & 0.65 & 0.41 & 0.49 & \\
\hline Watermelon & 0.83 & 0.41 & 0.81 & \\
\hline grapefruit & $1.00 \dagger$ & $1.00 \dagger$ & $1.00 \dagger$ & \\
\hline Cantaloupes & 1.00 & 0.63 & 1.00 & \\
\hline Strawberries & 0.84 & 0.16 & 0.38 & \\
\hline Pineapples & 0.75 & 0.41 & 0.75 & \\
\hline Peaches & $1.00 \dagger$ & $1.00 \dagger$ & $1.00 \dagger$ & \\
\hline Pears & 1.00 & $1.00 \dagger$ & 1.00 & \\
\hline Nectarines & $1.00 \dagger$ & $1.00 \dagger$ & $1.00 \dagger$ & \\
\hline Tangerines & $1.00 \dagger$ & $1.00 \dagger$ & $1.00 \dagger$ & \\
\hline Honeydew melon & $1.00 \dagger$ & $1.00 \dagger$ & $1.00 \dagger$ & \\
\hline Cherries & 0.75 & 0.43 & 0.75 & \\
\hline Avocados & 1.00 & 1.00 & 1.00 & \\
\hline Blueberries & 1.00 & 0.75 & 1.00 & \\
\hline Fresh vegetables & & & & 0.87 \\
\hline Tomatoes & 0.52 & 0.69 & 0.24 & \\
\hline Corn, sweet & 0.58 & 0.63 & 0.63 & \\
\hline Green beans & 1.00 & 1.00 & 1.00 & \\
\hline Carrots & 0.70 & 0.26 & 0.68 & \\
\hline Lettuce & 0.45 & 0.41 & -0.02 & \\
\hline Broccoli & $1.00 \dagger$ & $1.00 \dagger$ & $1.00 \dagger$ & \\
\hline Cucumber & 0.84 & 0.42 & 0.45 & \\
\hline Celery & 0.83 & 1.00 & 0.43 & \\
\hline Bell pepper & 0.54 & 0.49 & 0.69 & \\
\hline Spinach & 0.42 & 0.26 & 0.42 & \\
\hline Cauliflower & $1.00 \dagger$ & $1.00 \dagger$ & $1.00 \dagger$ & \\
\hline Asparagus & $1.00 \dagger$ & $1.00 \dagger$ & $1.00 \dagger$ & \\
\hline
\end{tabular}

${ }^{*}$ Kappa statistics for comparing the assessments between research staff and parents on each item; Percent agreement was reported when research staff or parents showed no variability in assessment (coding), and thus it was not suitable for Kappa statistics

†Percent agreement was used and calculated as follow: (number of agreements / number of agreements and number of disagreements) $\times 100 \%$

categories, (availability, visibility, and accessibility). This may be in part due to the large variety of these types of foods in the kitchen, as well as participants not clearly understanding which foods were characterized as whole grain products. Similarly, Boles et al. [18] reported that food items, such as cereal, may require increased training on reading food labels for sugar and fat content in order to make these distinctions when completing a food inventory. Therefore, for the final instrument, we made some modifications by providing guidelines for whole-grain breads and cereals, sweetened breakfast and cooked cereal with examples of the types of foods listed in each category. In addition, the item of "canned fruit in heavy syrup" was removed from the final assessment tool.
The individual fresh fruits and vegetables had high Kappa scores in terms of availability, visibility and accessibility, with the exception of strawberries (visibility), spinach (visibility), carrots (visibility), tomatoes (accessibility), and lettuce (accessibility). Since these items mainly were stored in the refrigerator, the parents who completed the assessment may not have clearly understood the term of visibility and accessibility when examining the refrigerator. Therefore, for future studies, clear but detailed instructions on how to assess the visibility and accessibility of food items in the refrigerator should be provided. Overall the current kappa scores for criterion validity of healthy and unhealthy food items and fresh fruits and vegetables were comparable to those reported by Fulkerson et al. [19] who also 
Table 4: Internal Consistency (Cronbach's alpha) and Test-Retest Reliability for 30-day Home Food Environment Survey (HFES, N=13)*

\begin{tabular}{|c|c|c|}
\hline Food and beverage item & ICC (P value) $)^{*}$ & $\begin{array}{l}\text { Cronbach's } \\
\text { alpha }\end{array}$ \\
\hline \multicolumn{3}{|l|}{ Unhealthy food and beverage items } \\
\hline Regular chips (potato chips, corn chips, tortilla chips) & $0.96(<0.0001)$ & \\
\hline Sweetened breakfast cereal or cooked cereal (not whole grain, > 6 g sugar per serving) & $0.86(0.001)$ & \\
\hline Sports drinks (e.g., Gatorade) & $0.80(0.007)$ & \\
\hline Milk (whole, 2\%) & $0.94(<0.0001)$ & \\
\hline Regular sodas - (e.g., Coke, 7-up, etc.) (not diet) & $0.94(<0.0001)$ & \\
\hline Regular yogurt (made with whole milk, with or without fruit) & $0.83(0.002)$ & \\
\hline Regular cheese (e.g., American, Cheddar, Swiss, Parmesan) & $0.79(0.005)$ & \\
\hline \multicolumn{3}{|l|}{ Healthy food and beverage items } \\
\hline Reduced fat cakes, brownies, muffins, cookies or pastries (already made) & $0.84(0.002)$ & \\
\hline Reduced fat chips, baked chips or pretzels & $0.46(0.12)$ & \\
\hline $\begin{array}{l}\text { Whole-grain cereals, breads, tortillas, brown rice or pasta (labeled "whole grain" or "whole } \\
\text { wheat", > } 3 \text { g fiber and < } 6 \text { g sugar/serving) }\end{array}$ & $0.92(<0.0001)$ & \\
\hline Fruit (e.g., apples, oranges) - fresh and ready-to-eat & $0.93(<0.0001)$ & \\
\hline Vegetables (e.g., carrots) - fresh and ready-to-eat & $0.69(0.02)$ & \\
\hline $100 \%$ fruit juice & $0.74(0.01)$ & \\
\hline Milk (1\% fat or fat free) & $0.93(<0.0001)$ & \\
\hline Reduced-fat yogurt (with or without fruit) & $0.78(0.003)$ & \\
\hline Reduced-fat cheese (e.g., low-fat cheddar, Swiss) & $0.07(0.43)$ & \\
\hline
\end{tabular}

${ }^{*}$ Intra-class Correlation Coefficient (ICC) was used to estimate the test-retest reliability

made a comparison between the staff and participant rating of home food inventories. However, that study included a larger sample size and was created for assessing a large variety of foods available in the home, without including a visibility assessment, as well as taking an extended period of time to complete.

In contrast, our tool was validated as a brief assessment tool which can be completed in 15 to 20 minutes and potentially be used independently by participants. Longer assessment tools may cause a potential burden to the participants when multiple assessments are involved. Although brief, our assessment tool captured the categories of healthy and unhealthy food and drink items which are essential for healthy eating and weight management.

The HFA was modified from the instrument developed by Boles et al. [18] which included the category of readiness to eat in addition to availability and accessibility. However, in the current assessment tool, the readiness to eat was replaced by visibility. Since our adapted instrument was designed to assess the home food environment of children aged 9 to 12 years, readiness to eat might not be as relevant to this age group as to the preschoolers targeted by Boles et al. [18]. Furthermore, the majority of the parents stated during the home visit that their pre-adolescents have access to all foods, without the assistance of a parent. Future home inventory studies in this age group may need to focus mainly on assessing food availability and visibility in the kitchen including countertops, tables, refrigerators and freezers.

The 18-item, 30-day Home Food Environment Survey (HFES) had high test-retest reliability and internal consistency scores. Since the one-time visit to the home may not capture all the foods that are in the home over a certain period of time, the addition of this survey (HFES) to HFA will provide researchers an overall understanding and a complete picture of pre-adolescent's home food environment, in terms of what healthy and unhealthy food items that the families usually have and what items are available, accessible, and visible in the home on a typical day. Our study also indicated that overall the summary scores of available healthy or unhealthy food items over the 30 day period prior to the home visit were positively associated with those on the day when the in-home assessment was performed although these results need to be confirmed in the future studies with larger sample size.

This is one of the very few studies which compared outcomes of the home food inventory assessment completed by the study participants to those reported by the research staff using the same measurement tool. The unique component of the instrument (HFA) is the inclusion of the assessment of visibility which is necessary for researchers in order to fully understand 
the home food environment of pre-adolescents. Also, using two instruments to capture the foods actually in the home at the time of the assessment and what is usually in the home over a 30-day time period is necessary to gain an overall complete picture of the home food environment and determine the key factors that may impact a pre-adolescent's dietary intake and potential weight gain.

There are limitations of the current study. First, the sample size was relatively small; however, in light of the nature of a pilot study, the majority of the food items from HFA had acceptable agreement scores between participants and research staff and test-retest reliabilities were high for items in HFES. Additionally, the internal consistency (Cronbach's alpha) was also high for the subscales as well as for the instruments. Second, our study participants may not reflect the general, diverse population since they were conveniently recruited from the local communities with relatively high income levels and whites being the majority. Furthermore, HFA did not assess the quantity of the food items since the response was only limited to "yes" or "no". However, our goal was to develop a brief home food assessment tool which is user-friendly and can be independently completed by the study participants. Attempting to collect data on a larger variety of foods or the actual quantity of foods would have compromised our aim and increase the burden on the participants.

\section{Conclusion}

In conclusion, the Home Food Assessment tool (HFS) was created to assess the availability, accessibility and visibility of healthy and unhealthy foods in the home of pre-adolescents. This tool was proved to be user-friendly and could be used effectively for data collection by study participants, making it feasible for multiple assessments of home food environment and alleviating the need for research staff home visits which can be expensive, time-consuming and potentially intrusive. This assessment tool in combination with the 30-day Home Food Environment survey (HFES) would be useful to obtain first-hand information regarding the home food environment of pre-adolescents, providing an avenue of direct intervention for weight management and obesity prevention in this target population.

\section{Acknowledgement}

This investigation was supported by the University of Nebraska-Lincoln Research Council Faculty Seed grant. The authors declare that they have no competing interests.

\section{Author's contributions}

All of the authors made substantial contributions to the study concept and design and analysis and interpretation of the data. MJN designed the study, recruited the participants, developed the instruments, collected the data and analyzed results. ML collected data and assisted in the development of the instruments. WC designed the study, developed the instruments and analyzed results, and was instrumental in the study. All authors contributed to prepare the manuscript and read and approved the final manuscript.

\section{References}

1. Ogden CL, Carroll MD, Kit BK, Flegal KM: Prevalence of obesity and trends in body mass index among US children and adolescents, 19992010. JAMA. 2012; 307(5): 483-90. doi: 10.1001/jama.2012.40.

2. Dietz WH: Health consequences of obesity in youth: childhood predictors of adult disease. Pediatrics. 1998; 101(3 Pt 2): 518-25.

3. Boonpleng W, Park CG, Gallo AM, Corte C, McCreary L, Bergren MD: Ecological influences of early childhood obesity: a multilevel analysis. West J Nurs Res. 2013 Jul;35(6): 742-59. doi: 10.1177/0193945913480275.

4. Larson N, Story M: A review of environmental influences on food choices. Annals of behavioral medicine : a publication of the Society of Behavioral Medicine. 2009; 38 Suppl 1:S56-73.

5. Rosenkranz RR, Dzewaltowski DA: Model of the home food environment pertaining to childhood obesity. Nutr Rev. 2008; 66(3): 123-40. doi: 10.1111/j.1753-4887.2008.00017.x.

6. Smith LP, Ng SW, Popkin BM: Trends in US home food preparation and consumption: analysis of national nutrition surveys and time use studies from 1965-1966 to 2007-2008. Nutr J. 2013; 12:45. doi: 10.1186/1475-2891-12-45.

7. Campbell KJ, Crawford DA, Salmon J, Carver A, Garnett SP, Baur LA: Associations between the home food environment and obesitypromoting eating behaviors in adolescence. Obesity(Silver Spring). 2007 Mar;15(3):719-30.

8. Hanson NI, Neumark-Sztainer D, Eisenberg ME, Story M, Wall M: Associations between parental report of the home food environment and adolescent intakes of fruits, vegetables and dairy foods. Public Health Nutr. 2005; 8(1): 77-85.

9. Ding D, Sallis JF, Norman GJ, Saelens BE, Harris SK, Kerr J, et al. Community food environment, home food environment, and fruit and vegetable intake of children and adolescents. J Nutr Educ Behav. 2012; 44(6): 634-8. doi: 10.1016/j.jneb.2010.07.003.

10. Neumark-Sztainer D, Story M, Perry C, Casey MA: Factors influencing food choices of adolescents: findings from focus-group discussions with adolescents. J Am Diet Assoc. 1999; 99(8): 929-37.

11. Neumark-Sztainer D, Wall MM, Story M, Perry CL: Correlates of unhealthy weight-control behaviors among adolescents: implications for prevention programs. Health Psychology, Vol 22(1), 2003; 88-98.

12. Befort C, Kaur H, Nollen N, Sullivan DK, Nazir N, Choi WS, et al. Fruit, vegetable, and fat intake among non-Hispanic black and non-Hispanic white adolescents: associations with home availability and food consumption settings. J Am Diet Assoc. 2006; 106(3): 367-73.

13. Cullen KW, Baranowski T, Owens E, Marsh T, Rittenberry L, de Moor C. Availability, accessibility, and preferences for fruit, $100 \%$ fruit juice, and vegetables influence children's dietary behavior. Health Educ Behav. 2003; 30(5): 615-26.

14. Brogan K, Idalski Carcone A, Jen KL, Ellis D, Marshall S, Naar-King S. Factors associated with weight resilience in obesogenic environments in female African-American adolescents. J Acad Nutr Diet. 2012; 112(5): 718-24. doi: 10.1016/j.jand.2012.02.004.

15. Bryant M, Stevens J. Measurement of food availability in the home. Nutr Rev. 2006; 64(2 Pt 1): 67-76.

16. Gattshall ML, Shoup JA, Marshall JA, Crane LA, Estabrooks PA: Validation of a survey instrument to assess home environments for physical activity and healthy eating in overweight children. Int J Behav Nutr Phys Act. 2008; 5: 3. doi: 10.1186/1479-5868-5-3. 
17. Bryant MJ, Ward DS, Hales D, Vaughn A, Tabak RG, Stevens J. Reliability and validity of the Healthy Home Survey: a tool to measure factors within homes hypothesized to relate to overweight in children. Int ] Behav Nutr Phys Act. 2008; 5: 23. doi: 10.1186/1479-5868-5-23.

18. Boles RE, Scharf C, Filigno SS, Saelens BE, Stark LJ. Differences in home food and activity environments between obese and healthy weight families of preschool children. J Nutr Educ Behav. 2013; 45(3): 222 31. doi: 10.1016/j.jneb.2012.09.012

19. Fulkerson JA, Nelson MC, Lytle L, Moe S, Heitzler C, Pasch KE. The validation of a home food inventory. The international journal of behavioral nutrition and physical activity 2008; 5: 55.

20.Wansink B, Painter JE, Lee YK. The office candy dish: proximity's influence on estimated and actual consumption. Int J Obes (Lond) 2006; 30(5): 871-5.

21. Sobal J, Wansink B. Kitchenscapes, Tablescapes, platescapes, and foodscapes: influences of microscale built environments on food intake. Environment and behavior 2007, 39: 124-142.

22. Krukowski RA, Harvey-Berino J, West DS. Differences in home food availability of high- and low-fat foods after a behavioral weight control program are regional not racial. Int J Behav Nutr Phys Act. 2010;7: 69. doi: 10.1186/1479-5868-7-69.
23. Lee AY, Sternthal B. The effects of positive mood on memory. Journal of Consumer Research 1999; 26(2): 115-127.

24. USDA Food and Nutrition Service. National School Lunch Program. Available from: http://www.fns.usda.gov/cnd/lunch/

25. Ogden CL, Kuczmarski RJ, Flegal KM, Mei Z, Guo S, Wei R, et al. Centers for Disease Control and Prevention 2000 growth charts for the United States: improvements to the 1977 National Center for Health Statistics version. Pediatrics 2002; 109(1): 45-60.

26. Krebs NF, Himes JH, Jacobson D, Nicklas TA, Guilday P, Styne D. Assessment of child and adolescent overweight and obesity. Pediatrics. 2007; 120 Suppl 4: S193-228.

27. Cronbach LJ. Test validation. In: Thorndike RL, Angoff WH, Lindquist $\mathrm{EF}$, editors. Educational Measurement. 2nd ed. Washington DC: American Council on Education; 1971.

28. Landis JR, Koch GG. The measurement of observer agreement for categorical data. Biometrics 1977; 33(1): 159-174.

29. Contento IR, Randell JS, Basch CE. Review and analysis of evaluation measures used in nutrition education intervention research. J Nutr Educ Behav. 2002; 34(1): 2-25. 